\title{
The Cultural and Physiological Gharacters of the Pediococci
}

\author{
By HELGE L. GÜNTHER AND HELEN R. WHITE \\ Bacteriology Department, Queen Elizabeth College (University of London), \\ London, W. 8
}

(Received 17 November 1960)

SUMMARY

The cultural and physiological characters of 89 strains of pediococci have been studied. Proposals are made for extension of the genus and its subdivision into two and possibly three groups. The reactions of eleven strains of Aerococcus viridans were also investigated.

\section{INTRODUCTION}

Organisms described as pediococci have been studied for some considerable time, mainly in relation to problems in the brewing industry (Balcke, 1884; Mees, 1934; Shimwell \& Kirkpatrick, 1939). More recently these organisms have been found in appreciable numbers in fermenting vegetable material (Pederson, 1929; Pederson \& Albury, 1950; Pederson, Albury \& Breed, 1954), in 'caecal faeces' of turkeys (Harrison \& Hansen, 1950), in the rumen of cows (Bauman \& Foster, 1956), in summer sausage (Deibel \& Niven, 1957), and in cheese (Naylor \& Sharpe, 1958; Dacre, $1958 a, b)$.

Systematic studies of the physiological characters (Pederson, 1949; Felton \& Niven, 1953; Jensen \& Seeley, 1954; Pederson et al. 1954) and of the nutritional requirements (Jensen \& Seeley, 1954) have led to recognition of the pediococci as belonging to a separate genus and to its classification within the family Lactobacillaceae in the tribe Streptococceae. This view has been incorporated in the seventh edition of Bergey's Manual (1957), where Pediococcus is described as a genus of Gram-positive cocci occurring singly and in tetrads, pairs and short chains, microaerophilic, generally catalase-negative, homofermentative, producing optically inactive lactic acid from carbohydrates, producing acidity and cloudiness in beer, and found as saprophytes in fermenting vegetable juices. Within the genus thus described two species only are recognized, $\boldsymbol{P}$. cerevisiae Balcke, 1884 , and $\boldsymbol{P}$. acidilactici Lindner, 1887, distinguished by their optimum growth temperatures and ability to grow in beer.

In the course of a study of bacterial changes occurring during the ensilage process (Hoffman, Wolf \& Barker, 1957) a large number of Gram-positive cocci was isolated which resembled the pediococci in certain characters. However, some of the silage isolates differed sufficiently from the descriptions of pediococci to suggest that the genus might be wider than previously thought. We have therefore made a survey of the cultural, physiological and serological characters of strains from a wide range of sources. Such an investigation seems to be particularly appropriate at the present time since the possibility of utilizing pediococci in fermentation processes has recently been proposed (Pederson \& Albury, 1950; Dacre, 1958a; Dr C. F. Niven 
Jun., personal communication). A possible relationship between the pediococci and members of the genus Aerococcus (Williams, Hirch \& Cowan, 1953) was suggested by Jensen \& Seeley (1954) and by Dr Ellen I. Garvie (personal communication). We have therefore included in the survey some Aerococcus strains.

\section{METHODS}

Sources of cultures. Eighty-nine isolates (including 39 new isolates from silage) were collected; 31 of these were representatives of named species. Most of the experimental work was carried out with all isolates; where this was not practicable isolates considered to be representative were selected for investigation.

In addition to the pediococcus cultures, 11 isolates of Aerococcus viridans were studied. A list of the isolates is given in Table 1, together with the references for the named species.

Maintenance of stock cultures and methods of cultivation. For maintenance of stock cultures, preparation of inocula and in all experimental work, 'Oxoid' tomato juice (TJ) broth or tomato juice (TJ) agar, adjusted to $\mathrm{pH} 6 \cdot 6$, were used unless otherwise stated. The following were exceptions to this rule: for strain Tc. 1 sodium chloride $(5 \%, \mathrm{w} / \mathrm{v})$ was added to the medium; and for the aerococci glucose Lemco broth (Shattock \& Hirsch, 1947) or glucose yeast extract (GY) agar (containing, as $\%$, w/v; peptone, 1.0 ; Yeastrel, 0.3 ; glucose, $1.0 ; \mathrm{NaCl}, 0 \cdot 25$; agar, 1.0 ; at $\mathrm{pH} 7 \cdot 4$ ) was used.

Cultures were incubated aerobically except where otherwise stated. The normal incubation temperature was $30^{\circ}$ except for isolates M-1, 8519 and 8520, for which it was $22^{\circ}$.

Stock cultures were maintained as stab cultures and stored at $4^{\circ}$. New transfers were made at 3-monthly intervals.

For use as inocula, vigorously growing cultures were obtained by making at least three successive subcultures. The incubation period was $24 \mathrm{hr}$. except for strains M-1, 8519, 8520 and Tc. 1 which required $72 \mathrm{hr}$. A 'standard' inoculum consisted of one loopful (about $4 \mathrm{~mm}$. diameter) of such a vigorously growing culture $/ 5 \mathrm{ml}$. test medium, and was used except where otherwise stated.

Morphology and staining reactions. The shape, arrangement and size of individual organisms were determined in Gram-stained smears prepared from $24 \mathrm{hr}$. cultures fixed by heat in the usual way. The Gram reaction (Jensen's modification; Mackie \& McCartney, 1953) of 24 and $48 \mathrm{hr}$. liquid cultures was determined. Hanging drop preparations of $24 \mathrm{hr}$. broth cultures were used to determine motility. Smears from $72 \mathrm{hr}$. agar cultures were examined for the presence of spores according to Fleming's method (Mackie \& McCartney, 1953) and Conklin's modification of Wirtz's method (Conklin, 1934). Muir's technique (Tanner, 1948) with 24 hr. agar cultures was used to search for capsules.

Cultural characters. The kind of surface colony was noted after incubation for $72 \mathrm{hr}$. and the form of growth in agar stab cultures observed after 48 or $96 \mathrm{hr}$. where necessary. Growth characters in liquid cultures were observed after incubation for 48 or $72 \mathrm{hr}$. Ability to form mucoid colonies on media containing sucrose was tested on the appropriate agar medium to which Seitz-filtered sucrose had been added to a final concentration of $5 \%(w / v)$. 


\section{Conditions affecting growth}

Except where otherwise stated, all results of experiments to determine the conditions which affected growth were recorded after $24,48 \mathrm{hr}$. and 7 days of incubation.

Table 1. Code number, species name, habitat and sources of cultures

Code numbers

F-166, E-66, N-82, K-64, K-106, B-168

A-1, C-1

2-170, 3-124, 3-129, 4-60, 4-89,

5-51, 5-61, 6-107, 6-159, 6-163,

D-32, D-95, D-118, N-91

FP-1, FP-6

P-60

P.c.

M-1

8519,8520

Tc. 1

PUE

EJ-1

M-31

A-140, A-181, B-137, B-190

SS-50, SS-61

SS-69, SS-101, SS-128

HY-22 $S$

BP-1, BP-2

559 (strain A2, Dacre, 1958a)

C-1, C-2, C-6, C-14

P-45, P-128, S-18, S-180, S-182,

S-188, S-190, S-191, S-290, S-333,

S-334, S-336, S-338, S-339, S-340,

S-342, S-344, S-447, S-524, S-525,

S-526, S-527, S-532, S-533, L-16,

L-20, L-22, L-24, L-92, L-95,

L-148, L-171, L-223, L-345,

L-347, L-351, L-352, L-354

$7592,7595,7597,7598,7599$,

7601, 7602

$7764,7765,7766,7767$
Species name

P. cerevisiae (Pederson, 1949)

P. cerevisiae (Pederson, 1949)

$P$. cerevisiae (Pederson, 1949)

$P$. cerevisiae (Pederson, 1949)

$\boldsymbol{P}$. cerevisiae (Garvie, 1959)

$P$. pentosaceus (Mees, 1934)

P. damnosus (Claussen, 1903)

$\boldsymbol{P}$. damnosus var. salicinaceus

(Mees, 1934)

P. halophilus (Mees, 1934)

$P$. urinae egui (Mees, 1934)

-

(1) Professor C. S. Pederson, N.Y. State Agriculture Experiment Station, Geneva, N.Y., U.S.A.

(2) Professor H. W. Seeley, Cornell University, Ithaca, New York. U.S.A.

(3) Dr C. F. Niven Jun., University of Chicago, Illinois, U.S.A.

(4) Technische Hoogeschool, Delft, Holland.

(5) Dr M. E. Sharpe, National Institute for Research in Dairying, Shinfield, near Reading.

(6) Dr T. Gibson, The Edinburgh and East of Scotland College of Agriculture, Edinburgh.

NCIB = National Collection of Industrial Bacteria, Torry Research Station, Aberdeen.

NCDO = National Collection of Dairy Organisms, Shinfield, near Reading.

NCTC $=$ National Collection of Type Cultures, London.

Oxygen requirement. Duplicate broth cultures were incubated aerobically, and anaerobically in an atmosphere of $\mathbf{9 5} \%(\mathrm{v} / \mathrm{v})$ hydrogen $+5 \%(\mathrm{v} / \mathrm{v})$ carbon dioxide. Visual estimation of growth was made after incubation for 24 or $72 \mathrm{hr}$. for slow growing strains.

Growth temperatures. To find the optimum growth temperature the amount of 
growth after incubation for $24 \mathrm{hr}$. at $22^{\circ}, 30^{\circ}$ and $37^{\circ}$ was estimated visually. With slow growing strains the results were read after $72 \mathrm{hr}$. of incubation. To indicate the range of growth temperatures, cultures were incubated at $10^{\circ}, 40^{\circ}$ and $45^{\circ}$ in water baths controlled to within $\pm 1^{\circ}$.

Growth at $\mathrm{pH} 9 \cdot 0$ and $\mathrm{pH} 4 \cdot 2$. In these experiments the technique was based on that described by Shattock \& Hirsch (1947) for testing growth of streptococci at pH 9.6. The following modifications were made: tomato juice (TJ) broth was substituted for glucose Lemco broth; to obtain the medium at $\mathrm{pH} \mathrm{9.0} \mathrm{suitable}$ quantities of the $0.1 \mathrm{M}$-glycine buffer recommended by Shattock \& Hirsch (1947) were added; for the medium at $\mathrm{pH} 4 \cdot 2$, sodium acetate + acetic acid buffer (Clark, 1928) at $0.04 \mathrm{M}$ was selected, since some inhibitory effects were noted at higher concentrations.

Tolerance to sodium chloride and Teepol. Ability to grow in 4 and $6.5 \%(\mathrm{w} / \mathrm{v})$ sodium chloride and in $\mathbf{0 . 0 1 , 0 . 0 5}$ or $0.1 \%$ Teepol was tested in TJ broth cultures.

Growth in wort, hopped wort and beer. The amount of growth was observed visually in wort, hopped wort and beer. The wort and hopped wort (about $6 \%$ hops) were obtained through the courtesy of Mr C. S. Everitt (Watney Mann Breweries, London) and the beer was commercially available bottled Carlsberg Lager. These media were sterilized by Seitz filtration.

\section{Biochemical tests}

Media used for biochemical tests were based on those commonly used for testing lactobacilli since optimal media for pediococci have not yet been devised. Where consistent with satisfactory results the lactobacillus media were simplified. Known positive and negative control cultures were included in each test series.

Catalase activity. Felton, Evans \& Niven (1953) found that a medium of low carbohydrate content (YTG) gave a greater number of positive reactions than a medium of high carbohydrate content (APT). Gutekunst, Delwiche \& Seeley (1957) recommended that cultures to be used for catalase tests should be neutralized after incubation. In the present work, preliminary tests were carried out with 12 isolates of pediococci to compare nutrient broth (containing $(\%, w / v)$ : Yeastrel, 0.3; peptone, $1.0 ; \mathrm{NaCl}, \mathbf{0 . 5}$; at $\mathrm{pH} 7 \cdot 0$ ) with $\mathrm{TJ}$ broth and $\mathrm{GY}$ broth as media for catalase tests. No qualitative differences were found but the reactions in nutrient broth were sometimes stronger. In view of this and of the recommendations of the above workers, nutrient broth was retained as the experimental medium. Twice the 'standard inoculum' (above) was used for $5 \mathrm{ml}$. medium and incubation was carried out for $24 \mathrm{hr}$., or $72 \mathrm{hr}$. when necessary. Two ml. of freshly prepared $3 \%$ (10 vol.) hydrogen peroxide were added and the cultures examined up to $30 \mathrm{~min}$. for visible gas bubbles.

Haemolysis. Horse blood $(5 \%, \mathrm{v} / \mathrm{v})$ agar streak plates were prepared and incubated both aerobically and anaerobically. Pour plates were also made and incubated similarly. Results were read after incubation for $48 \mathrm{hr}$. and again after overnight storage at $4^{\circ}$.

Liquefaction of gelatin. Stab cultures were incubated at optimum temperature and examined for liquefaction after chilling at 7, 14 and 28 days. The nutrient gelatin medium had the same formula as the nutrient broth, with the addition of $14 \%(w / v)$ gelatin. 
Reduction of nitrate. Incubation was carried out for 7 days in the medium of Davis (1955) from which salt solutions ' $A$ ' and ' $B$ ' had been omitted. Cultures were then tested for the presence of nitrite and of nitrogen gas as described in the Manual for Pure Culture Study (1954). The medium was tested for the presence of nitrite before incubation and for residual nitrate after incubation.

Production of ammonia from arginine. The method described by Niven, Smiley \& Sherman (1942) was used.

Carbohydrate reactions. Yeast-extract peptone broth (containing, \% w/v: peptone, 1.0 ; yeast extract, $0.5 ; \mathrm{NaCl}, 0.5 ; \mathrm{MgSO}_{4}, 0.05 ; \mathrm{MnSO}_{4}, 0.05$; at $\mathrm{pH} 7.0$ ) was used as a basal medium for fermentation tests, and Seitz-filtered carbohydrate added to give $1 \%(\mathrm{w} / \mathrm{v})$ final concentration. Acid and gas production were determined after 7 days of incubation (indicator, $0.04 \%(w / v)$ bromcresol purple, added after incubation), since preliminary results had shown that many isolates, especially fresh ones, were slow in producing acid. Acid once produced was not masked by subsequent production of alkaline substances. The carbohydrates tested were: arabinose, xylose, glucose, fructose, maltose, lactose, sucrose, trehalose, raffinose, inulin, dextrin, glycerol, mannitol, sorbitol, salicin.

Hydrolysis of aesculin. The method of Davis (1955) was used, except that Tween 80 (which according to Jensen \& Seeley, 1954 is not required by pediococci) and salt solutions ' $A$ ' and ' $B$ ' were omitted from the medium, and sodium chloride $(0.2 \%, w / v)$, manganese sulphate $(0.05 \%, \mathrm{w} / \mathrm{v})$ and magnesium sulphate $(0.05 \%$, $\mathrm{w} / \mathrm{v}$ ) were added. The cultures were examined daily for 7 days.

Production of acetylmethylcarbinol from glucose and from lactose. Tests were carried out in the medium of Swartling (1951), modified in one series of experiments by the substitution of glucose for lactose. Cultures were incubated for 6 days and tested for acetylmethylcarbinol by Barritt's (1936) modification of the Voges-Proskauer test.

Final hydrogen ion concentration. Glucose $(1 \%, \mathrm{w} / \mathrm{v})$ yeast-extract liquid cultures were incubated for 18 days and the final $\mathrm{pH}$ values measured electrometrically. Some isolates grew poorly in this medium but the use of tomato juice broth was considered inadvisable because of its natural content of reducing sugar which might have resulted in the production of acids from compounds other than glucose.

Production of carbon dioxide from glucose. The method of Gibson \& Abd-el-Malek (1945) was used; cultures were examined daily for gas production during a 2-week incubation period.

Reaction in litmus milk. Litmus milk cultures were examined for reduction of indicator, change in $\mathrm{pH}$ value or coagulation during 28 days of incubation.

Type of lactic acid produced. The method of Pederson, Peterson \& Fred (1926) was followed except that a continuous ether extraction apparatus was used, extracting the sample for $48 \mathrm{hr}$. The zinc content of the isolated zinc lactate was determined by the titrimetric method of Kolthoff \& Sandell (1950) and the optical rotation determined polarimetrically, using the anhydrous salt in $1 \%(\mathrm{w} / \mathrm{v})$ aqueous solution. Six pediococcus strains were examined.

Utilization of ammonium salts as sole source of nitrogen. The medium and method described by Hucker (1924) were used. Incubation continued for 14 days.

Folinic acid requirement. The method used was a modification of that outlined in the Difco Manual (1953). Tests were carried out in triplicate in $4 \mathrm{ml}$. amounts in 
$12 \times 80 \mathrm{~mm}$. EEL colorimeter tubes. Growth after $18 \mathrm{hr}$. of incubation was measured turbidimetrically with an EEL colorimeter. The folinic acid used in these experiments was supplied as 'leucovorin' by Lederle Laboratory Division Ltd. and was used in concentrations of $0,0 \cdot 15,0 \cdot 3$ and $0 \cdot 6 \mathrm{~m} \mu \mathrm{g}$. $/ \mathrm{ml}$. Twenty isolates were examined for this requirement.

\section{RESULTS}

A comparison of named pediococcus cultures and unnamed strains showed certain features to be shared by all; these are regarded as characteristic of the genus. A number of additional features was possessed by some but not all isolates examined. On the basis of these additional features, two distinct physiological groups could be differentiated and there was some indication of a less well-defined third group. The results are presented in two sections: (i) characters common to all 'pediococci'; (ii) characters used to differentiate the groups; the results are listed in Table 2. The reactions given by the aerococci are included for comparison. The criteria on which the subdivisions have been based are summarized in Table 3.

\section{Characters common to all pediococci}

Morphology and staining reaction. The organisms were spherical, occasionally ovoid, strongly Gram-positive, ranging in diameter from $0 \cdot 36$ to $1 \cdot 43 \mu$. They were arranged in clusters, tetrads, pairs or singly, were non-motile, non-sporeforming and not encapsulated.

Cultural characters. Surface colonies were greyish-white, smooth, circular, low convex with entire margins. Growth in stab culture was beaded throughout the entire length of the stab, with a small amount of surface growth. Mucoid colonies were not formed on agar media containing sucrose.

Growth conditions. In the media described, growth was similar under aerobic and anaerobic conditions. The optimum temperature was $30^{\circ}$ for all but three isolates; for these it was $22^{\circ}$. Growth was initiated at $10^{\circ}$. No strains were able to grow at pH 9.0. Wort provided a suitable substrate but the addition of hops exerted some inhibitory effect; no growth took place in the particular beer used.

Biochemical tests. A small zone of $\beta$ haemolysis was produced on blood agar by a few isolates only. With the majority of isolates a zone of 'bleaching' similar to that described by Davis \& Rogers (1939) for lactobacilli was noted. The organisms did not liquefy gelatin, did not reduce nitrate to nitrite or nitrogen gas, nor did they produce detectable amounts of carbon dioxide from glucose. Litmus milk was reduced, acidified and coagulated only rarely. The lactic acid produced by the six isolates tested was optically inactive. Small amounts of steam-volatile acids were produced in addition to lactic acid. No growth was observable in media in which ammonium salts constituted the sole source of nitrogen.

\section{Characters on which was based differentiation into groups (Tables 2 and $\mathbf{3}$ )}

Group I. This group includes 38 isolates, of which 27 were cultures received as Pediococcus cerevisiae, one was received as $P$. pentosaceus, and the following were unnamed: C-1, C-2, C-6, EJ-1, SS-50, SS-128, BP-1, BP-2, P-45, P-128.

Members of this group were distinguished readily by: size of surface colonies on tomato juice agar, varying between 0.5 and $\mathbf{1 . 2} \mathrm{mm}$. in diameter; abundant growth 


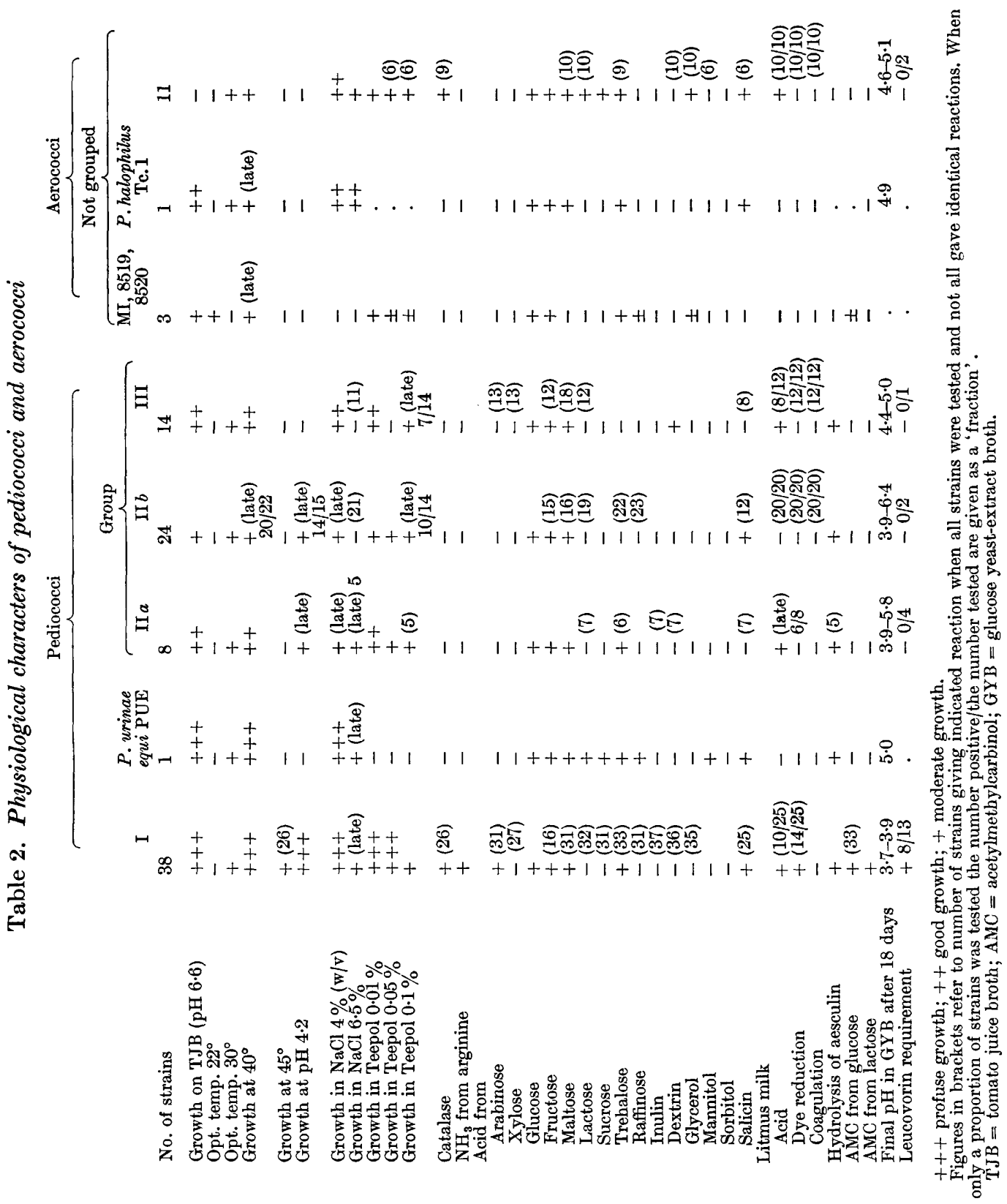


in tomato juice broth; consistently low final $\mathrm{pH}$ value (3.7-3.9) in GY broth;

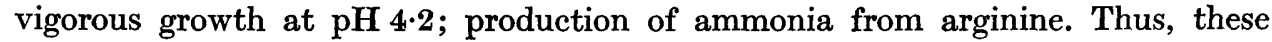
isolates form a well-defined and easily recognizable group. In addition, 25 of these isolates were capable of growth at $45^{\circ}$, and 33 produced acetylmethylcarbinol from glucose and lactose. Catalase activity was demonstrated in 26 isolates. All isolates were tolerant of $4 \%(\mathrm{w} / \mathrm{v})$ sodium chloride but a concentration of $6.5 \%$ delayed the growth of 27 isolates, to some degree. The addition of Teepol at 0.01 and $0.05 \%(\mathrm{v} / \mathrm{v})$ did not affect growth but at $0 \cdot 1 \%$ initiation of growth was delayed by $24 \mathrm{hr}$. for 3 isolates. Eight isolates in this group exhibited a specific requirement for leucovorin.

Group II. This group consisted of the cultures received as Pediococcus halophilus (Tc. 1) and the following 32 unnamed isolates: M-31, A-140, A-181, B-137, B-190, SS-61, SS-101, HY-22s, S-18, S-180, S-182, S-188, S-190, S-191, S-290, S-333, S-334, S-335, S-338, S-339, S-340, S-342, S-344, S-447, S-524, S-525, S-526, S-527, S-532, S-533, C-14, SS-69. Its members differed from group I in: producing surface colonies on tomato juice agar of only $\mathbf{0 \cdot 3 - 0 \cdot 4} \mathrm{mm}$. diameter; showing less vigorous growth in tomato juice broth; absence of catalase activity; failure to produce ammonia from arginine; no acetylmethylcarbinol from glucose or lactose. They were unable to grow at $45^{\circ}$ or in $4 \%(\mathrm{w} / \mathrm{v}) \mathrm{NaCl}$ within $24 \mathrm{hr}$. and grew at $\mathrm{pH} 4 \cdot 2$ only after prolonged incubation (up to 7 days). Two subdivisions were recognized within this group. The 24 isolates listed (S-18, SS-69), unlike the others, grew poorly in tomato juice broth, failed to grow at $40^{\circ}$ within $24 \mathrm{hr}$. and generally did not produce acid from trehalose.

Table 3. Main characters on which subdivision of pediococci may be based

\begin{tabular}{|c|c|c|c|c|c|c|c|c|c|c|}
\hline \multirow[b]{2}{*}{ Species name } & \multirow[b]{2}{*}{ Group } & \multirow{2}{*}{$\begin{array}{l}\text { Opti- } \\
\text { mum } \\
\text { growth } \\
\text { temp. }\end{array}$} & \multirow{2}{*}{$\begin{array}{c}\text { Diameter } \\
\text { of surface } \\
\text { colonies } \\
\text { on TJA } \\
(\mathrm{mm} .)\end{array}$} & \multirow[b]{2}{*}{$\begin{array}{l}\text { Growth } \\
\text { in TJB }\end{array}$} & \multirow[b]{2}{*}{$\begin{array}{l}\text { Growth } \\
\text { pH } 4.2\end{array}$} & \multicolumn{2}{|c|}{$\begin{array}{c}\text { Growth in } 4 \%(w / v) \\
\mathrm{NaCl}\end{array}$} & \multirow{2}{*}{$\begin{array}{l}\mathrm{NH}_{3} \\
\text { from } \\
\text { argi- } \\
\text { nine }\end{array}$} & \multirow{2}{*}{$\begin{array}{c}\text { AMC } \\
\text { from } \\
\text { glu- } \\
\text { cose }\end{array}$} & \multirow{2}{*}{$\begin{array}{l}\text { Acid } \\
\text { from } \\
\text { dex- } \\
\text { trin }\end{array}$} \\
\hline & & & & & & $24 \mathrm{hr}$. & $48 \mathrm{hr}$. & & & \\
\hline$P$. cerevisiae & 1 & $30^{\circ}$ & $0.6-1.2$ & +++ & +++ & $++t$ & $++t$ & + & $\begin{array}{c}+ \\
\text { almost } \\
\text { always }\end{array}$ & - \\
\hline P. 'parvulus' & 11 & $30^{\circ}$ & $0 \cdot 3-0 \cdot 4$ & + & Late & - & \pm & - & - & - \\
\hline P. damnosus? & 111 & $\begin{array}{l}\mathbf{3 0}^{\circ} \\
\mathbf{2 2}^{\circ}\end{array}$ & $\begin{array}{l}0 \cdot 6-1 \cdot 0 \\
0 \cdot 3-0 \cdot 6\end{array}$ & $\begin{array}{l}++ \\
\text { Late }\end{array}$ & - & ++ & ++ & - & $\overline{+}$ & $\begin{array}{l}+ \\
-\end{array}$ \\
\hline P. halophilus? & & $30^{\circ}$ & $0 \cdot 6-0 \cdot 8$ & Late & - & $\begin{array}{l}5 \% \\
\text { essenti }\end{array}$ & - & - & - & - \\
\hline
\end{tabular}

TJA $=$ tomato juice agar $; \mathbf{T J B}=$ tomato juice broth; $\mathbf{A M C}=$ acetylmethylcarbinol. +++ Growth abundant; ++ good growth; + moderate growth.

Possible group $I I I$. This group was less well defined but is tentatively suggested for the following 14 unnamed isolates: L-16, L-20, L-22, L-24, L-92, L-95, L-148, L-171, L-223, L-345, L-347, L-351, L-352, L-354. These isolates resembled group I in size of surface colonies on tomato juice agar and abundant growth in tomato juice broth but could be differentiated by their inability to grow at $\mathrm{pH} 4 \cdot 2$ even when incubated for 7 days and by their failure to produce ammonia from arginine. They differed also from the majority of group $I$ isolates in: failure to grow at $45^{\circ}$; absence of catalase activity; failure to produce acetylmethylcarbinol from glucose or lactose. They could be separated from group II isolates by: colony size; absence 
of growth at pH $4 \cdot 2$; ability to grow in media containing $4 \%(\mathrm{w} / \mathrm{v}) \mathrm{NaCl}$ within 24. hr.; acid production from dextrin.

Other isolates. Some isolates did not fall readily into any of the above three groups. Pediococcus urinae equi was indistinguishable in cultural characteristics from members of group I but differed from the majority of those in failure to grow at $\mathrm{pH} 4 \cdot 2$, inability to produce ammonia from arginine and acetylmethylcarbinol from glucose or lactose, higher final $\mathrm{pH}$ value in glucose broth $(\mathrm{pH} \mathrm{5.0)}$ and lower resistance to Teepol. It may be regarded as a member of a possible subgroup of group I.

$P$ ediococcus damnosus strain M-1 and $\boldsymbol{P}$. damnosus var. salicinaceus strains 8519 and 8520 were readily distinguishable from the other pediococci by their lower optimum growth temperature of $\mathbf{2 2}^{\circ}$. They did not produce ammonia from arginine and $\boldsymbol{P}$. damnosus strain M-I produced acetylmethylcarbinol from glucose but not from lactose.

Pediococcus halophilus strain Tc. 1 was exceptional in its requirement for $5 \%$ $(w / v)$ sodium chloride; in most of its other reactions it resembled members of group III.

Aerococci. These organisms were fairly uniform in character. They resembled the pediococci, as defined above, in morphology, failure to hydrolyse gelatin, to reduce nitrate to nitrite or to utilize ammonia salts as sole source of nitrogen, and in absence of gas formation from glucose. Unlike the pediococci, however, the aerococci grew well in nutrient broth, grew vigorously at $\mathrm{pH} \mathrm{9.0}$ and were highly sensitive to acidity (even pH 6.8 exerted an inhibitory effect). Nine of the 11 isolates were catalase-positive, one was negative and one gave a variable reaction. However, in the media used all these aerococci were strictly aerobic.

\section{DISCUSSION}

\section{Relationship of pediococci to other genera}

The results of the present work provide additional evidence in support of the recognition of a separate genus Pediococcus as suggested by Balcke (1884), Mees (1934) and more recently by Pederson (1949), Felton \& Niven (1953) and Jensen \& Seeley (1954). All members of this genus are easily recognizable by their morphology, mode of division and high lactic acid-producing capacity. We think, however, that the genus should include a rather wider range of organisms than suggested by Pederson et al. (1954) and by Jensen \& Seeley (1954).

The present results show that the leucovorin (folinic acid) requirement, suggested by Felton \& Niven (1953) and by Jensen \& Seeley (1954) to be typical of all pediococci, is, in fact, restricted only to some isolates within our group I. Another property considered by some investigators to be an outstanding character of pediococci (Balcke, 1884; Lindner, 1887; Claussen, 1903) was the ability to multiply vigorously in beer, although more recently strains have been described which failed to multiply in this medium (Mees, 1934; Shimwell, 1949; Pederson, 1949). Pederson (1957) in Bergey's Manual (7th ed.) describes the genus as producing acidification and some degree of clouding in beer, and the two species listed are separated according to their optimum growth temperature and ability to grow in beer and hopped wort. Pediococcus cerevisiae Balcke 1884, the type species, is regarded as capable of growth in wort, hopped wort and beer, while $P$. acidilactic $i$ Lindner 1887 will grow in unhopped 
wort but not in beer. Of the isolates studied in the present work, none showed growth in the particular beer used for the test. The use of the criterion 'growth in beer', without further qualifications as to the kind in which growth is tested, is however of little value, as beers may show wide variation in acidity, in hop content, in ethanol and carbon dioxide concentration, and in the degree of 'attenuation' which influences the quantity of nutrients available in the medium.

The present investigation confirms the separation of the genus Pediococcus from the other closely related genera. It resembles the lactic acid streptococci in requiring complex media for growth as shown by Jensen \& Seeley (1954), and in being homofermentative as demonstrated by Pederson et al. (1954) and confirmed in this study. However, as reported previously (Günther, 1959), the pediococci are also clearly distinguishable from streptococci on the basis of morphology and mode of division. Morphology, homofermentative character and production of optically inactive lactic acid, as found in the present work and previously by Pederson et al. (1954) serve to differentiate the pediococci from the genus Leuconostoc.

The pediococci closely resemble micrococci in morphology and mode of division but may be separated from them by consideration of their biochemical characters. Although biochemical characters are often found to be variable and therefore unreliable as diagnostic criteria, all of those investigated in the present study have been shown to be stable over a period of at least 18 months. Where isolates obtained by other authors were investigated, the results were in general the same as those previously described. Therefore it seems justifiable to use such characters as differential criteria. Thus pediococci can be differentiated from micrococci on the basis of their failure to: grow on simple media; utilize ammonium salts as sole source of nitrogen; reduce nitrate to nitrite or nitrogen gas; liquefy gelatin.

The differentiation between pediococci and aerococci is less satisfactory on the basis of present results. Their morphology and mode of division is similar and neither group is capable of reducing nitrate, hydrolysing gelatin or utilizing ammonium salts as sources of nitrogen. Jensen \& Seeley (1954) and Dr Ellen I. Garvie (personal communication) have suggested that the two groups may be related sufficiently to be included in the same genus. However, in contrast to the pediococci, the aerococci grew well on simpler media, grew only under aerobic conditions, were highly sensitive to acid, but grew profusely in alkaline media ( $\mathrm{pH} \mathrm{9.0)}$. Such differences provide sufficient evidence for separating the two groups but further experimental data are yet required before establishing their separation at generic or specific level.

\section{Subdivision of the pediococci}

A subdivision of the pediococci into three groups, as indicated in the section on results, is suggested. Although there is some variability within each proposed group, experience in the laboratory handling of these organisms has enabled us to recognize easily the three groups by their cultural characters and we feel justified in suggesting the subdivision of the pediococci in this way.

Pederson (1949) and Jensen \& Seeley (1954) recognized only one species, Pediococcus cerevisiae Balcke, the type species. In a later paper, Pederson et al. (1954) suggested two possible additional species of which the first $(a)$ produced slime, and the second $(b)$ possessed a higher optimum growth temperature. For organism $(a)$ the name $\boldsymbol{P}$. viscosus Lindner was suggested, and for organism $(b)$ either $\boldsymbol{P}$. acidilactici 
Lindner or $\boldsymbol{P}$. hennebergi Sollied. In the seventh edition of Bergey's Manual, Pederson (1957) lists two species : the type species $\boldsymbol{P}$. cerevisiae Balcke; $\boldsymbol{P}$. acidilactici Lindner characterized by an optimum growth temperature of $40^{\circ}$ and failure to grow in beer. In the present survey no isolates were observed which produced slime (in presence of sucrose) or had a high optimum temperature.

The reactions characteristic of the group I organisms of this study are in general the same as those described for the strains of Pediococcus cerevisiae Balcke studied by Pederson (1949), Felton \& Niven (1953), Jensen \& Seeley (1954) and Dacre $(1958 a)$. It would appear justifiable, therefore, to apply the species name $\boldsymbol{P}$. cerevisiae Balcke to this group, which includes the isolates received as $\boldsymbol{P}$. pentosaceus (Mees), strain A2 (NCDO 559) of Dacre (1958a), and strain P-60 previously known as Leuconostoc mesenteroides $\mathrm{P}-60$ but classified recently with the pediococci by Garvie (1959).

Pederson et al. (1954) compared strain Pediococcus urinae equi with their culture of $\boldsymbol{P}$. cerevisiae and concluded that this organism should not be included in the pediococci because of lower acid-production properties. The present study confirmed the inability of $\boldsymbol{P}$. urinae equi to produce a low final $\mathrm{pH}$ value but showed that it was indistinguishable from $\boldsymbol{P}$. cerevisiae in most of its morphological and cultural characters. It can therefore only be regarded as a variant of that species. The features of the group II isolates are sufficiently distinct to warrant the recognition of a separate species. No description could be found in the literature of such a species and the name Pediococcus parvulus is suggested.

Group III is much less well defined. The characters of this group resemble those described by Andrews \& Gilliland (1952) for a dextrin-fermenting organism which they named Streptococcus damnosus var. diastaticus. A culture of the latter organism was not available for comparative study. It is felt that insufficient evidence is at present available on which to base the establishment of this group at specific rank.

Three isolates received as Pediococcus damnosus strain M.1 and $\boldsymbol{P}$. damnosus var. salicinaceus strains 8519 and $\mathbf{8 5 2 0}$ failed to fit into any of the three groups described. None of them fermented salicin. Many authors have found the fermentation of pentoses and salicin to be variable and Pederson (1949) classified such strains as $\boldsymbol{P}$. cerevisiae. However, the three isolates we received resembled each other and differed from $P$. cerevisiae (group I) in a number of characters (see Table 2; it may be noted that they all have a low optimum temperature). They might form the nucleus of a fourth group should other isolates with such characters be noted in future and should be regarded as members of a species $\boldsymbol{P}$. damnosus.

The culture received as Pediococcus halophilus (Tc.1) was quite distinct in character (especially in its requirement for $5 \%, \mathrm{w} / \mathrm{v}, \mathrm{NaCl}$ ) and, should additional strains be isolated, a fifth group might be recognized. Deibel \& Niven (1960) described strains of pediococci isolated from meat-curing brines which were salt tolerant and produced dextrorotatory lactic acid from glucose. Deibel \& Niven considered that their strains may be closely related to the marine micrococcus Gaffkya homari (Sniesko \& Taylor, 1947) and also to Aerococcus viridans. They suggested that all these organisms should be placed in the genus Pediococcus with the species name Pediococcus homari nov.comb. Further investigation is needed before it can be decided whether this species and the $P$. halophilus of Mees (1934) are the same. It 
would seem that a group of salt-tolerant or even halophilic pediococci might indeed constitute a fifth species.

Serological work to be published in the following paper (Günther \& White, 1961) confirms a subdivision into at least three groups as here suggested.

\section{REFERENCES}

Andrews, J. \& GilliLand, R. B. (1952). Super-attenuation of beer: A study of three organisms capable of causing abnormal attenuations. J. Inst. Brerv. 58, n.s. 49, 189.

BALCKe, J. (1884). Über häufig vorkommende Fehler in der Bierbereitung. Wschr. Brau. $1,181$.

BARRITT, M. M. (1936). The intensification of the V.-P. reaction by addition of $\alpha$-naphthol. J. Path. Bact. 42, 441.

Bauman, H. E. \& Foster, E. M. (1956). Characteristics of organisms isolated from the rumen of cows fed high and low roughage rations. J. Bact. 71, 333.

Bergey's Manual of Determinative Bacteriology (1957). 7th ed., ed. R. S. Breed, E. G. D. Murray \& N. R. Smith, London: Baillière, Tindall and Cox Ltd.

Clark, W. M. (1928). The Determination of Hydrogen Ions, 3rd ed. London: Baillière, Tindall and Cox Ltd.

Claussen, N. H. (1903). Étude sur les bactéries dites sarcines et sur les maladies qu'elles provoquent dans la bière. C.R. Lab. Carlsberg, 6, 64 .

Conkurn, M.E. (1934). Mercurochrome as a bacteriological stain. J. Bact. 27, 30.

DACRE, J. C. $(1958 a)$. Characteristics of a presumptive pediococcus occurring in New Zealand cheddar cheese. J. Dairy Res. 25, 409.

DACre, J. C. (1958b). A note on the pediococci in New Zealand cheddar cheese. J. Dairy Res. 25, 414 .

Davis, G. H. G. (1955). The classification of lactobacilli from the human mouth. J. gen. Microbiol. 13, 481.

DAvis, J. G. \& Rogers, H. J. (1939). The reactions of streptococci and lactobacilli in blood agar. J. Hyg., Camb. 39, 446.

Deibel, R. H. \& Niven, C. F., Jun. (1957). Pediococcus cerevisiae: a starter culture for summer sausage. Bact. Proc. 14.

Deibel, R. H. \& Nrven, C. F., Jun. (1960). Comparative study of Gaffkya homari, Aerococcus viridans, tetrad forming cocci from meat curing brines and the genus Pediococcus. J. Bact. 79, 175.

Difco Manual (1953). 9th ed., Difco Lab. Inc., Detroit 1, Mich., U.S.A.

Felton, E. A. \& Niven, C. F., Jun. (1953). The identity of 'Leuconostoc citrovorum, strain 8081 '. J. Bact. 65, 482.

Felton, E. A., Evans, J. B. \& Niven, C. F. Jun. (1953). Production of catalase by the pediococci. J. Bact. 65, 481.

Garvie, E. I. (1959). Reclassification of Leuconostoc mesenteroides P-60 as a pediococcus. Nature, Lond. 183, 1411.

Gibson, T. \& ABD-EL-MaLeK, Y. (1945). The formation of carbon dioxide hy lactic acid bacteria and Bacillus licheniformis and a cultural method of detecting the process. J. Dairy Res. 14, 35.

GüNTHER, H. L. (1959). Mode of division of pediococci. Nature, Lond. 183, 903.

GüNTHER, H. L. \& WhITE, H. R. (1961). Serological characters of the pediococci. J. gen. Microbiol. 26, 199.

Gutekunst, R. R., Delwiche, E. A. \& Seeley, H. W. (1957). Catalase activity in Pediococcus cerevisiae as related to hydrogen ion activity. J. Bact. 74, 693.

Harrison, A. P., Jr. \& Hansen, P. A. (1950). The bacterial flora of the cecal feces of healthy turkeys. J. Bact. 59, 197.

Hoffman, H., Wolf, J. \& Barker, A. N. (1957). Microbial changes in the ensilage process. J. appl. Bact. 20, xv.

Hucker, G. J. (1924). Studies on the Coccaceae. III.-A study of the general characters of the micrococci. Bull. N.Y. St. agric. Exp. Sta. 101, 36. 
Jensen, E. M. \& Seeley, H. W. (1954). The nutrition and physiology of the genus Pediococcus. J. Bact. 67, 484.

Kolthoff, I. M. \& Sandell, E. B. (1950). Textbook of Quantitative Inorganic Analysis, p. 577. London: Macmillan and Co., Ltd.

LINDNER, P. (1887). Ueber ein neues in Malzmaischen vorkommendes Milchsäure bildendes Ferment. Z Zbl. Bakt. Abt. 1, 2, 340 (Abstract).

Mackie, T. J. \& McCartney, J. E. (1953). Handbook of Practical Bacteriology, 9th ed. Edinburgh and London: E. and S. Livingstone Ltd.

Manual of Pure Culture Study of Bacteria (1954). Soc. Amer. Bact., Geneva, N.Y., Leaflet V., 54 .

MeEs, R. H. (1934). Onderzoekingen over de Biersarcina. Thesis, Delft.

Naylor, J. \& Sharpe, M. E. (1958). Lactobacilli in Cheddar Cheese. II. Duplicate cheeses. J. Dairy Res. 25, 421.

Niven, C. F., Jun., Sminey, K. L. \& Sherman, J. M. (1942). The hydrolysis of arginine by streptococci. J. Bact. $43,651$.

Pederson, C. S. (1929). The types of organisms found in spoiled tomato products. Bull. N.Y. St. agric. Exp. Sta. 150.

Pederson, C. S. (1949). The genus Pediococcus. Bact. Rev. 13, 225.

Pederson, C. S. (1957). In Bergey's Manual of Determinative Bacteriology (1957), 7th ed., p. 529. Ed. Breed, E. S., Murray, E. G. D. \& Smith, N. R. London: Baillière, Tindall and Cox Ltd.

Pederson, C. S. \& Albury, M. N. (1950). Effect of temperature upon bacteriological and chemical changes in fermenting cucumbers. Bull. N.Y. St. agric. Exp. Sta. 744, 1.

Pederson, C. S., Albury, M. N. \& Breed, R. S. (1954). Pediococcus cerevisiae, the beer sarcina. Wallerstein Labs. Communs. 17, 7.

Pederson, C. S., Peterson, W. H. \& Fred, E. B. (1926). The forms of lactic acid produced by pure and mixed cultures of bacteria. J. biol. Chem. 68, 151 .

ShatTock, P. M. F. \& Hrrsch, A. (1947). A liquid medium buffered at pH 9.6 for the differentiation of Streptococcus faecalis from Streptococcus lactis. J. Path. Bact. 59, 495.

ShImweld, J. L. (1949). Brewing bacteriology. VI.-The lactic acid bacteria (Family Lactobacteriaceae). Wallerstein Labs. Communs. 12, 71.

Shimwerx, J. L. \& Kirkpatrick, W. F. (1939). New light on the 'Sarcina' question. J. Inst. Brew. 45, n.s. 36, 137.

Snieszio, S. F. \& TAYlor, C. C. (1947). A bacterial disease of the lobster (Homarus americanus). Science, 105, 500.

Swarturng, P. F. (1951). Biochemical and serological properties of some citric acid fermenting streptococci from milk and dairy products. J. Dairy Res. 18, 256.

Tanner, F. W. (1948). Practical Bacteriology. New York: John Wiley and Sons, Inc.

Williams, R. E. O., Hrrch, A. \& Cowan, S. T. (1953). Aerococcus, a new bacterial genus. J. gen. Microbiol. 8, 475 . 